\title{
ANALYSIS OF THE INFLUENCE OF TRANSDUCER FREQUENCY ON THE ULTRASONIC MEASUREMENT OF CONCRETE HOMOGENEITY
}

\author{
Dalibor Kocáb*, Petr Misák, Barbora Jindrová, Martin Alexa, \\ TOMÁŠ VYMAZAL
}

\author{
Brno University of Technology, Faculty of Civil Engineering, Veveri 331/95, 602 00 Brno, Czech Republic \\ * corresponding author: dalibor.kocab@vutbr.cz
}

\begin{abstract}
The paper analyses the influence of transducer frequency on the determination of concrete homogeneity using the ultrasonic pulse velocity test. Transit time measurements were made on a $590 \times 590 \mathrm{~mm}$ concrete slab, with $110 \mathrm{~mm}$ in thickness, in a raster of $5 \times 5$ points, which means the slab was tested in 25 places. The tests were made using a Pundit PL-200 ultrasonic tester using transducers set at 54, 82, and $150 \mathrm{kHz}$. Two types of measurements were performed - spot measurements of the ultrasonic pulse transit time at each point and full area scanning. The paper is concluded by an evaluation of the concrete slab's homogeneity measured by different transducers and techniques in addition to a statistical analysis of how the results are affected by the transducer frequency.
\end{abstract}

KEYWORDS: Ultrasonic pulse velocity test, concrete, concrete homogeneity, transducer frequency.

\section{INTRODUCTION}

The ultrasonic pulse velocity test, alongside the rebound hammer test discussed e.g. in [1, is one of the most widespread testing methods in civil engineering [2. The principle of the ultrasonic pulse velocity test is sending ultrasonic pulses into the material and measuring their transit time. The pulses travel through different materials at a different velocity, depending on their properties 3 . In concrete it is generally true that the pulse velocity is lower in poor quality concrete or in damaged areas (including micro-defects) 4. Ultrasonic pulse transit time is regulated by ČSN EN 12504-4 [5] and ČSN 731371 [6], and can be used for measuring:

- concrete homogeneity,

- the presence of cracks or air voids,

- material properties - modulus of elasticity, compressive or tensile strength,

- changes in the above-listed properties over time (e.g. by degradation).

Some of the main advantages of the ultrasonic pulse velocity test is that it is completely non-destructive, which makes it suited for repeated measurements in the same place and convenient for testing in a laboratory or on site. Civil engineering usually uses frequencies of $20-150 \mathrm{kHz}$; sometimes even up to $500 \mathrm{kHz}$. Higher frequencies improve the instrument's resolution, making the measurement more accurate, but also substantially weakening the pulse, which asks for a compromise depending on the measured element's thickness as well as other parameters [7].

The motivation for this experiment was the fact that a Vikasonic ultrasonic tester [8] was procured by the co-authors [9]. This device is primarily designed for the non-destructive determination of the setting time in cement pastes or for monitoring the progress of their setting and hardening at an early age, which is something that has been addressed in a number of papers [10, 11]. The Vikasonic uses transducers that operate at $54 \mathrm{kHz}$. A specimen has the shape of the Vicat ring and can be made of a paste, mortar, or concrete, which makes this device rather suitable. The Vicat ring, however, is only $40 \mathrm{~mm}$ tall and thus the transducers are positioned at this distance as well. With a measuring base of this size, however, it would be better to use higher transducer frequencies [5, 6]. The goal of the paper was to determine how the transducer frequency affects the ultrasonic pulse transit time in concrete during homogeneity measurement.

\section{EXPERIMENT}

Because it offers a wider range of settings during transit time measurement, the experiment was performed with a Pundit PL-200 [12] instead of a Vikasonic, since they both operate on the same principle. The actual measurement involves repeated sending of ultrasonic pulses and detecting them as they travel through the material. When applied to concrete, the ultrasonic pulse velocity test usually uses two transducers (a transmitter and a receiver) placed on opposite sides of the specimen or structure, measuring the time it takes for the ultrasonic pulse to travel from one transducer to the other, which is then used to calculate the velocity $v_{L}$ [7].

Measurements were performed on a concrete slab with $110 \mathrm{~mm}$ in thickness and $590 \times 590 \mathrm{~mm}$ in width and length using three types of transducers - 54, 82 and $150 \mathrm{kHz}$. A $5 \times 5$ raster of 25 measurement places was laid out on the slab, see Fig. 1. The slab was 


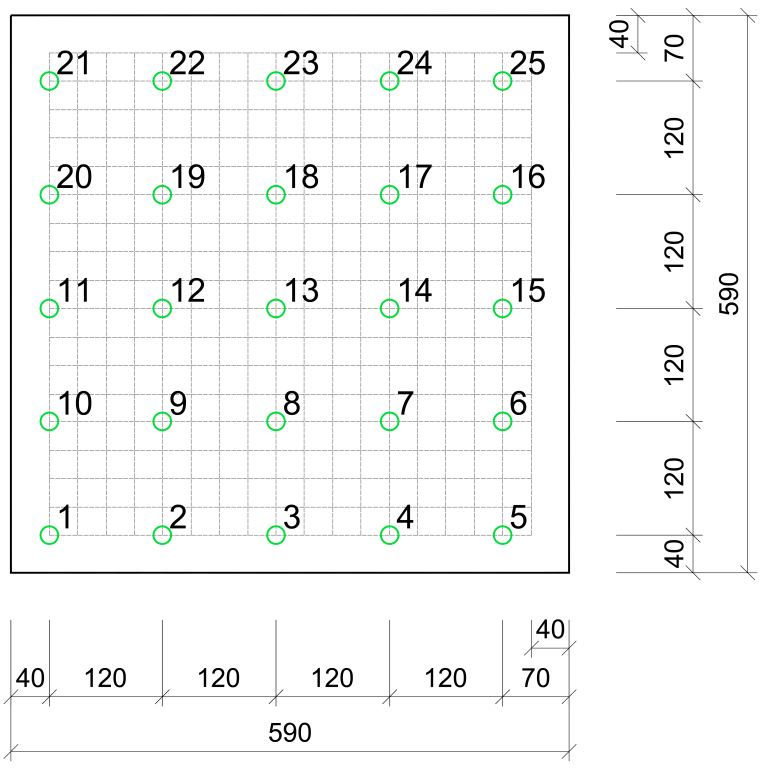

Figure 1. Spot measurement layout.

scanned three times using each pair of transducers in an area scanning mode. This is a mode that the Pundit PL-200 offers and is able to draw the quality distribution over an area of the concrete being tested. The results take the form of contour lines that show different areas in different colours based on the ultrasonic pulse velocity $v_{L}$. Even during the measurement, one can see which areas are of better or worse quality (in other words, where the ultrasonic pulses travel more quickly or slowly). The area scanning mode was used to determine the velocity $v_{L} 75$ times - three measurements in the raster of 25 points, using all three transducer types. Then the Pundit PL-200 was switched to a mode measuring the ultrasonic pulse transit time $t_{0}$. Given the fact that the device does not support $82 \mathrm{kHz}$ transducers, the points of the raster on the test slab were measured using only transducers of 54 and $150 \mathrm{kHz}$. Otherwise the measurement procedure was the same as during area scanning (the sequence of measuring points) and both transducer frequencies were tested three times. Thus, 75 values of transit time $t_{0}$ were measured, from which 75 values of $v_{L}$ were calculated (three per measuring point). Aside from homogeneity testing, a statistical analysis of measurements by each transducer was performed. The homogeneity testing followed ČSN 732011 [13, where the key criterion is the value of the coefficient of variance $v_{L}$, which, in homogeneous concrete, must not exceed $4.0 \%$.

\section{Results And Discussion}

The statistical comparison of test results was made following procedures of the analysis of variance (ANOVA) and a two-sample $t$-test on a level of significance of 0.05. These statistical tests were set up so as to enable the assessment of the mean values of the test results; in case this hypothesis is rejected, the sets of results can be considered significantly different. First, an assessment was made whether the results are comparable at repeated measurements and unchanged instrument settings. No statistically significant deviation was found there. Fig. 2 shows the results in the form of contour lines created from the average value of $v_{L}$ for the corresponding point of measurement. For the purposes of further processing, the results were compiled into five files of 75 values of $v_{L}$. Additionally, data normality was tested on a level of significance of 0.01 . Histograms of the test results are shown in Fig, 3 .

Fig. 4 shows a box plot of the values of $v_{L}$. In the case of spot measurements using 54 and $150 \mathrm{kHz}$ transducers, there was a statistically significant deviation in the values of $v_{L}$, which was also confirmed by one-way hypothesis testing. It can thus be said that using $150 \mathrm{kHz}$ transducers produces much higher values of $v_{L}$ than using $54 \mathrm{kHz}$ ones. The same conclusion was also reached by an analysis of the results of area scanning, which says that measurements with $150 \mathrm{kHz}$ transducers return values that are statistically more significant than measurements made with $82 \mathrm{kHz}$ transducers. The values of $v_{L}$ measured by 54 or $82 \mathrm{kHz}$ transducers, however, do not show any difference. In addition, data from spot and area scanning at the same frequency were compared. No statistically significant deviation was found there. It can thus be stated that the resulting values of ultrasonic wave velocity is influenced primarily by transducer frequency. However, it must be noted that the experiment outcomes may have been affected by the small measurement base or the non-homogeneity of the slab being tested. This would explain why the coefficient of variance exceeded $4.0 \%$ in all measurements.

\section{Conclusion}

The experiment invites the following conclusions:

- Transducer frequency has a statistically significant role in determining the final value of ultrasonic pulse velocity $v_{L}$ in concrete.

- The precise value of $v_{L}$ thus cannot be precisely ascertained, nor can it be used to calculate any property of concrete (e.g. dynamic modulus of elasticity), which corresponds with the recommendations in ASTM C597-16 14.

- On the other hand, the ultrasonic pulse velocity test appears well-suited for determining concrete homogeneity, since it only observes variability in the values of $v_{L}$. This method can just as well be used for determining the progress of degradation in concrete, e.g. due to exposure to freeze-thaw cycles, as the absolute value of $v_{L}$ is not deciding; only its decrease over time.

- The Vikasonic can be used for measuring the setting time of cement composites. However, given the small measurement base and the low frequency of 

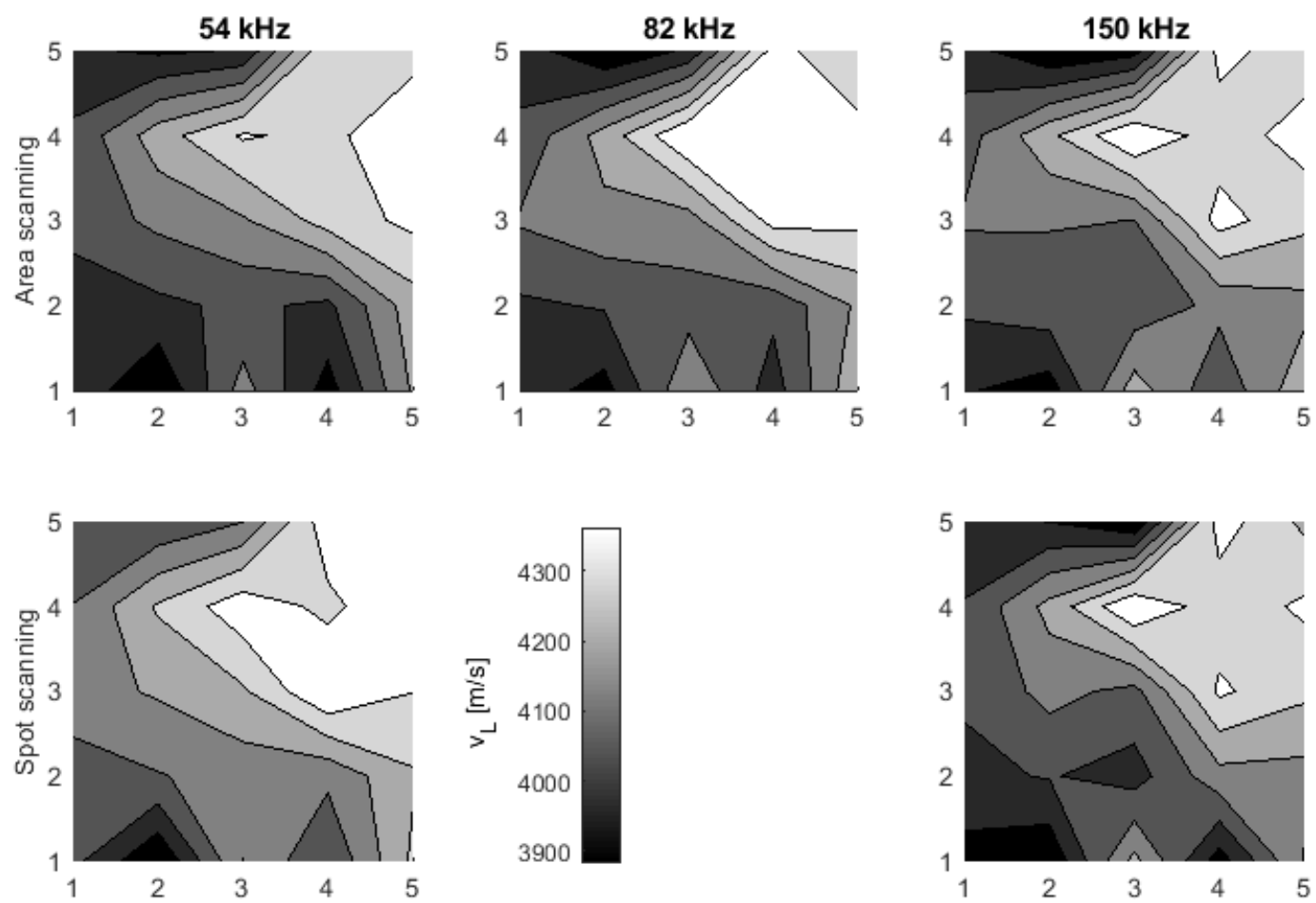

Figure 2. A contour diagram of the test results of area and spot scanning.
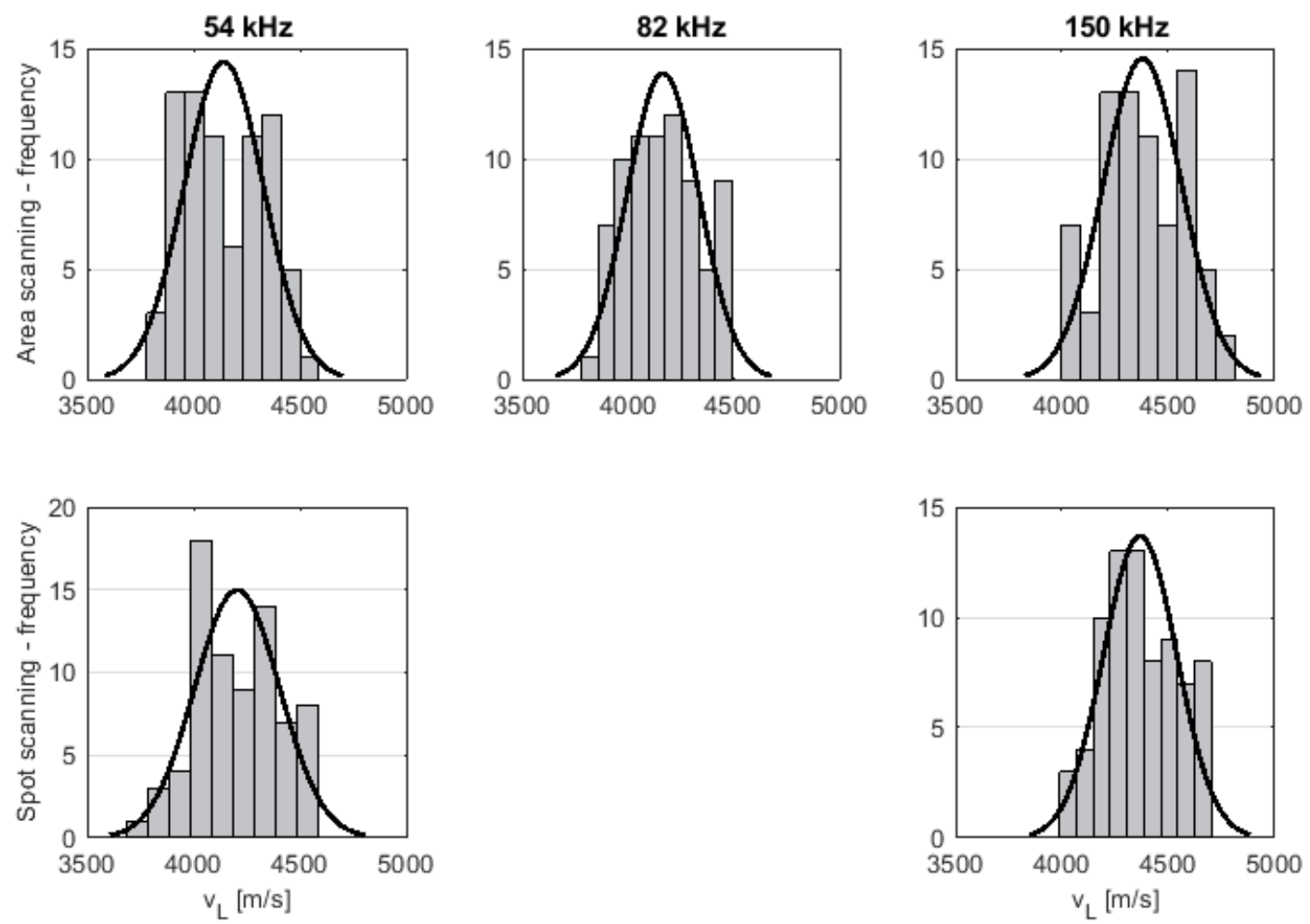

Figure 3. Test result histograms. 

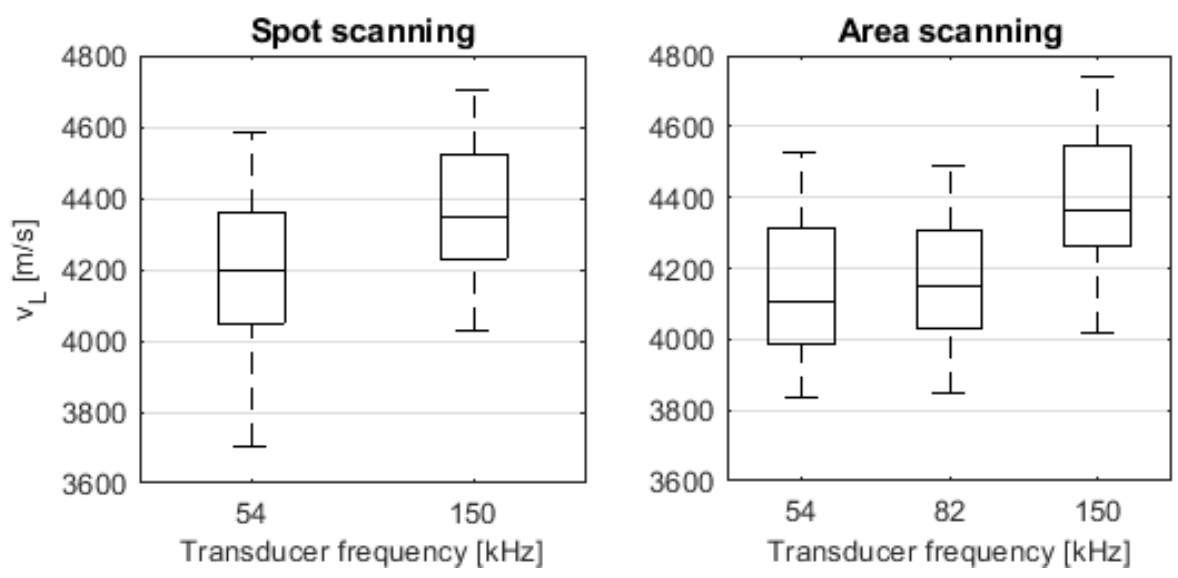

Figure 4. Box plots of test results.

transducers $(40 \mathrm{~mm}$ and $54 \mathrm{kHz})$, this instrument is not entirely suitable for determining material properties such as the modulus of elasticity.

- Any ultrasonic device thus appears ill-suited for measuring the elastic modulus. There is a possible option of correcting the values based on some other simultaneous measurement (e.g. loading under compression).

\section{ACKNOWLEDGEMENTS}

This paper has been written as part of the project No. GA17-14302S "Experimental analysis of the early-age volume changes in cement-based composites", supported by the GA0 - Czech Science Foundation and project No. FAST/FCH-J-18-5595 "Reduction of chemical and autogenous shrinkage of alkaline activated slag".

\section{REFERENCES}

[1] P. Cikrle, D. Kocáb, B. Kucharczyková, O. Anton. In situ determination of the elastic modulus of concrete by means of ultrasonic pulse method. In 24 th Concrete Days 2017, vol. 272 of Solid State Phenomena, pp. 70-75. Trans Tech Publications, 2018. DOI:10.4028/www.scientific.net/SSP.272.70

[2] V. M. Malhotra, N. Carino (eds.). Handbook on Nondestructive testing of concrete. CRC Press Inc., 2nd edn., 2004.

[3] V. Özkan, I. H. Sarpün, S. Tuncel. Nondestructive Testing of Materials and Structures, vol. 6 of RILEM bookseries, chap. Relative effects of porosity and grain size on ultrasonic wave propagation in marbles, pp. 373379. Springer, 2012. DOI:10.1007/978-94-007-0723-8_54

[4] A. M. Neville. Properties of concrete. Pearson, New York, 5th edn., 2011.

[5] ČSN EN 12504-4 - Testing concrete - Part 4: Determination of ultrasonic pulse velocity. Standard, ČNI, Prague, 2005.
[6] ČSN 731371 - Non-destructive testing of concrete Method of ultrasonic pulse testing of concrete. Standard, ÚNMZ, Prague, 2011.

[7] B. Kopec, et al. Nedestruktivní zkoušení materiálů a konstrukcí: (nauka o materiálu IV). Akademické nakladatelství CERM, Brno, 2008.

[8] S. T. Systems. Vikasonic - measuring the early setting and hardening with ultrasonic waves. http: //www.schleibinger.com/cmsimple/en/?Setting_ and_Maturity:Ultrasonic_Setting_Measurement

[9] I. Rozsypalová, O. Karel, B. Kucharczyková, et al. Monitoring of the setting and early hardening with ultrasonic waves. In Rehabilitation and Reconstruction of Buildings, vol. 776 of Key Engineering Materials, pp. 51-54. Trans Tech Publications, 2018. DOI:10.4028/www.scientific.net/KEM.776.51

[10] A. Gibson, D. Ciancio. Nondestructive Testing of Materials and Structure, vol. 6, chap. Early-Age Ultrasonic Testing of Concrete and Shotcrete using Embedded Sensors, pp. 485-490. Springer, Dordrecht, 2013. DOI:10.1007/978-94-007-0723-8 69

[11] N. De Belie, C. Grosse, J. Kurz, H.-W. Reinhardt. Reinhardt HW Ultrasound monitoring of the influence of different accelerating admixtures and cement types for shotcrete on setting and hardening behavior. Cement and Concrete Research 35:2087-2094, 2005. DOI:10.1016/j.cemconres.2005.03.011.

[12] Proceq. Pundit ultrasonic pulse velocity and pulse echo tomography.

https://www.proceq.com/compare/ pundit-ultrasonic-pulse-velocity-and-pulseecho-testing/.

[13] ČSN 732011 - Non-destructive testing of concrete structures. Standard, ÚNMZ, Prague, 2012.

[14] ASTM C597-16 - Standard Test Method for Pulse Velocity Through Concrete. Standard, ASTM International, West Conshohocken, 2016. 